Arab World English Journal (AWEJ) Volume 12. Number4 December 2021

DOI: https://dx.doi.org/10.24093/awej/vol12no4.20

Pp.302- 316

\title{
A Sociomaterial Perspective of the Challenges of Implementing the Communicative Approach in Saudi State Schools
}

\author{
Rajaa Mahmoud Fallatah \\ Department of Curriculums and Instructions, College of Education \\ Umm Al-Qura University, Saudi Arabia \\ Email: rmfalltah@uqu.edu.sa
}

Received: 9/30/2021

Accepted:11/15/2021

Published: 12/15/2021

\section{Abstract}

Despite its dominance in the field of teaching English as a second/foreign language, the implementation of the Communicative Language Teaching (CLT) approach continues to be challenging and problematic. A similar set of constraints - including but not limited to challenges related to educational cultures, contextual and conceptual factors, and lack of authentic materials and facilities - have been reported as factors hindering CLT implementations in many contexts. Language teaching and learning materials and facilities are crucial elements that have been found to affect communicative language teaching implementation. However, the issue of how those material elements can affect CLT implementation has rarely been the focus of research in CLT implementation studies. In this paper, the researcher examines the effect of language teaching and learning materials on teachers' ability to teach communicatively. Thus, informed by sociomateriality this paper attends to a gap in the literature about how material elements of the curriculum hinder the implementation of the communicative language teaching approach in the Saudi context. The data examined in this study were collected through classroom observations and semi-structured interviews. The analysis of the findings indicated that material elements in the curriculum exerted agency and power, hindering teachers' ability to teach communicatively and learners' ability to improve their learning experiences. The report concludes with practical implications related to the complexity of curriculum development and implementation and the emergent nature of such processes as webs of entangled human/nonhuman relations that give rise to education.

Keywords: Actor-network theory, communicative language teaching approach, complexity theory, curriculum development, language teaching materials, sociomateriality

Cite as Fallatah, R. M.(2021). A Sociomaterial Perspective of the Challenges of Implementing the Communicative Approach in Saudi State Schools. Arab World English Journal, 12 (4) 302316. DOI: https://dx.doi.org/10.24093/awej/vol12no4.20 


\section{Introduction}

Although Communicative Language Teaching (CLT) is widely used, there are many reports in the literature indicating that CLT implementation in some EFL contexts has been and continues to be challenging and problematic (Bax, 2003; Didenko \& Pichugova, 2016; Kumaravadivelu, 2006). Several factors have been reported in the literature as to why CLT implementation into ESL/EFL contexts has proven to be a difficult task (see for example, Jin \& Cortazzi, 2011; Zhang, 2020 in China; Li, 1998 in South Korea; Karakas, 2013; Ozsevik, 2010 in Turkey; Alakrash, 2021 in Syria). Some propose that this problem is due to cultural and conceptual differences (Richards \& Rodger, 2014) - as CLT was born in and reflected a Western view of education (Holliday, 1994). However, the current paper illustrates a new perspective of understanding CLT challenges. This paper focuses on material use in CLT classrooms and addresses its relationship with micro-level (i.e., classroom practices) and macro-level (i.e., educational system and policies) challenges of implementing CLT in the Saudi context.

In summary, this paper addresses two concerns. The first is to engage in recent scholarly efforts to investigate language teaching and learning from a sociomaterial perspective. The second concern illustrates the challenges of implementing CLT into the Saudi educational context focusing on challenges that resonate with sociomaterial orientations. This paper addresses the following research questions:

1. To what extent do language teaching and learning materials affect CLT implementation in Saudi state schools?

2. How can sociomateriality extend scholarly efforts to examine curriculum implementation in valuable directions?

The following section addresses two key constructs in this study. The first examines the conceptual understanding of sociomateriality, sociomaterial orientations, and the concept of language teaching and learning materials. The second offers a brief definition of the Communicative Language Teaching approach and a review of its implementation in ESL/EFL contexts and Saudi Arabia.

\section{Literature Review}

\section{Conceptualizing Sociomateriality}

Material elements in education (including but not limited to textbooks, technology, facilities, and resources) are usually dismissed or treated as background (Fenwick, Edwards \& Sawchuk, 2011). However, from a sociomateriality point of view, these material assemblages can play a role in creating the reality of the educational phenomenon and stabilizing ways of producing centers of power (Fenwick \& Doyle, 2018). Within this view, learning emerges through relations between teachers and learners on one end and materials in the classroom environment on the other end (Fenwick et al., 2011). Although empirical inquiry into how materials are used in language education has emerged, in recent years, as an innovative area of research (Tomlinson \& Masuhara, 2018), the field is still understudied and undertheorized (Guerrettaz, Engman \& Matsumoto, 2021). Indeed, research into language classroom practices tends to study human aspects and linguistic systems rather than focusing on material and nonhuman aspects (Canagarajah, 2018; Toohey, 2019; Pennycook, 2018). According to Guerrettaz et al. (2021), this might be due to the narrow conceptualization of the concept of 
materials in the field of language learning and teaching, which tends to (a) overlook the complexities of how materials affect learners, teachers, language pedagogy and, language use within classroom settings; and (b) focus on only one type of materials (i.e., textbooks). Thus, this paper aims to illustrate how language teaching and learning materials go beyond such a shallow understanding. They can play an influential role in and strongly affect teaching and learning practices within the classroom.

Sociomateriality is an orientation that is present in diverse social science frameworks and an approach to educational research rather than a single unified theory (Fenwick et al., 2011). Sociomateriality draws on a myriad of theories and ontologies from a wide range of disciplines (Guerrettaz et al., 2021). Fenwick (2015) has asserted that sociomaterial perspectives to educational research have been influenced by many theoretical orientations - including complexity theory, actor-network theory, and others - that share the principal premise that there is no distinction between social phenomena and materiality. However, complexity theory is increasingly influencing educational research suggesting the examination of the dynamics of emergence within educational contexts (see Barad, 2007; Davis \& Sumara, 2006; Fullan, 2003). Complexity theory as a materialist orientation is discussed later in this paper.

In the sphere of language education, sociomaterialism moves the field away from the proclivity toward linguistic exceptionalism (Canagarajah, 2018) - i.e., the tendency to prioritize structural language - towards acknowledging the significance of the numerous "polysemiotic resources in the social world" (Guerrettaz et al., 2021, p. 9) within language classrooms. Drawing on Fenwick's (2010) conceptualization, the material - in this paper - includes tools, technologies, objects, and bodies as agentic actors not inherently distinct from humans as designers and users. Understanding language classrooms as a networked reality - where social and material elements are viewed as equal contributors to the network - is consistent with actor-network theory (Fenwick, 2015). This understanding - of material elements - challenges centering human consciousness and intention in teaching practices and foregrounds those material elements (Fenwick, 2010). Thus, from a sociomaterial perspective, educational research illustrates how materials actively impact teaching and learning practices and how educational processes are sociomaterial achievements (Fenwick, 2015). Actor-network theory is yet another sociomaterial orientation that will be addressed later in this paper.

According to Fenwick and Dahlgren (2015), emphasis has been placed on recognizing how material actors would move in practice and learning and relate to social actors in complex systems. As a result, a rich body of literature has arisen on how sociomaterializing educational processes could configure educational actors, showing possibilities for alternative ways to understand curriculum and different approaches to pedagogical interventions (Fenwick et al., 2011). This type of research can also help in highlighting how sociomaterial approaches to education might enrich our understanding of the enactment of education policies (Fenwick \& Edwards, 2010; Fenwick \& Landri, 2012). Thus, from this perspective, educational researchers could ask how different elements in the curriculum would act on one another to affect its implementation and how these interactions would produce different outcomes. Moreover, acknowledging that curricular change can be uncertain and unpredictable (Fullan, 2003) - as the system continuously adapts and changes patterns affecting practice (Fenwick \& Dahlgren, 2015) - can raise some fundamental questions for educators. For example, educational researchers could 
ask questions such as: how would teaching practice be interconnected with and affected by articulated syllabus plans, and how can these plans make textbooks more powerful than teachers? How might educational reform dominated by pre-packaged and imported curricula inhibit its successful implementation? How could centralized educational systems affect attempts at educational reform? This paper aims to open the discussion to answer some of these questions.

Thus, sociomateriality enables educational inquiry to identify patterns of materiality in educational settings while simultaneously accounting for the frequently unpredictable dynamism of classrooms (Fenwick et al., 2011). Consequently, then, it breaks down any artificial boundaries between the material and social aspects of education by foregrounding the entangled interrelationships of the material world vis-à-vis social structures (Guerrettaz et al., 2021). Fenwick (2015), in the Sage Handbook of learning, has pointed out that sociomateriality enables educational researchers to consider systematic as well as unpredictable aspects of education. Through the sociomaterial lens, concepts such as students, teachers, learning activities and spaces, texts, pedagogy, and curriculum are understood as effects of heterogeneous relations rather than foundational categories or objects with distinct isolated properties. Therefore, sociomateriality can help illustrate what comprises learning and the dynamics that constitute education (Fenwick, 2010). Finally, Fenwick (2015) has suggested that sociomaterial perspectives offer approaches for understanding power relations within educational practices: not just how powerful webs become assembled but also how "to intervene, disturb or amplify those webs" (p. 84).

\section{Sociomaterial Orientations: Complexity Theory and Actor-Network Theory}

As mentioned above, there are numerous orientations to sociomateriality. However, two sociomaterial perspectives - complexity theory and actor-network theory - are selected for discussion in this paper. Complexity theory is derived from evolutionary biology and physics but has become increasingly influential in educational research (Fenwick, 2015). From a complexity theory orientation, teaching and learning are seen as emergent assemblages that create new transcendent unity of actions - resultant from changes in the social and material elements in the system comprising them and in which they participate - that could not have been achieved independently (Fenwick, 2010). As a result, one could assume that, from a complexity theory perspective, teaching and learning could not be organized according to externally imposed blueprints - e.g., syllabus distribution plans and policies imposed from the top - in hierarchical managerial systems. But, rather educational practices should be inclusively treated as unpredictable to maintain sustainable, effective teaching and learning practices.

From an actor-network theory perspective, teaching and learning practices - seen as a joint exercise within networks performed through nonhuman and human beings - are performed in assembling and maintaining networks (Fenwick, 2010). This perspective is linked explicitly to the politics - i.e., power relations - through which practices - e.g., teachers' adherence to textbooks come to be assembled and extend to translate the identities and behaviors of each actor in the system - e.g., textbooks, teachers, etc. Thus, From an actor-network theory lens (see, for example, Braidotti, 2013; Latour, 2005), educational research illustrates how do educational practices such as testing and performativity and accountability procedures - and objects - such as textbooks - become stabilized as powerful assemblages that can limit, enhance or disrupt teaching processes and possibilities of learning. 
However, it is pertinent to point out here that although actor-network theory and complexity theory might be derived from different theoretical roots, Fenwick et al. (2011) has indicated that they bear some significant resemblances. Both approaches explore the webs of entangled human/nonhuman actions that give rise to educational systems. Both perspectives conceptualize knowledge as emerging - simultaneously with material elements - "in webs of interconnections between heterogeneous entities, human and nonhuman" (Fenwick, 2010, p. 106). Therefore, as sociomaterial approaches, both can invite those in the sphere of education to consider the material aspects of schooling (technologies, materials, resources) that might exert forces and might be entangled with what would appear to be a human intention, engagement and change by focusing on how can agency be distributed across people, technology, and things (Landri, 2015).

\section{Conceptualizing Language Teaching and Learning Materials within Sociomaterialism}

In the contemporary era of language education, teachers and learners have access to a wide array of language learning tools, apps, websites, and content with numerous tasks and activities designed to enhance and accelerate teaching and learning processes (Thorne, Hellermann \& Jakonen, 2021). Nevertheless, there is a small body of research concerned with investigating additional language education materials from a sociomaterial perspective (Guerrettaz et al., 2021). Harwood (2014) has categorized research on teaching materials in TESOL into a three-way classification as follows: material content (analyzing textbooks outside the classroom context); material consumption (examining how teachers and learners use textbooks), and material production (concerned with how textbooks are designed and distributed). The current paper falls under the material consumption level of Harwood's (2014) categories. Yet, this paper would broaden the concept of materials to go beyond textbooks - as described in Harwood's (2014) classification - to the use of everything teachers and learners use to make English learning more efficient - including but not limited to textbooks and teacher-designed worksheets (Harwood, 2021).

In this paper, the concept of language materials is understood as an entangled - i.e., the interrelationship between human and nonhuman elements (see Fenwick, 2015) - and emergent i.e., generated and recognized through interaction between social and material actors (see Barad, 2007) - assemblage - i.e., heterogonous gathering of polysemiotic elements (see Toohey, 2019) of different entities that exert power, influence, and agency in the language classroom context. Understanding language teaching and learning materials from a sociomaterial perspective, this paper draws on Guerrettaz et al.'s (2021) empirically based - drawing on seven empirical classroom-based studies of materials use in language education - definition of materials. Guerrettaz et al. (2021) have defined language materials as:

"(a) physical entities, (b) texts, (c) environments, (d) signs, and (e) technologies within the perceptual field of the learner(s) or teacher(s); these are used with the ultimate intention of facilitating [language learning and teaching] and in some sort of principled way" (p. 11).

The five categories described in the definition mentioned above include materials - such as textbooks, prints, whiteboards, images, words, gestures, digital and online resources, classrooms, PowerPoint slides, smartphone apps, projectors, tablets, Internet, Wi-Fi, and laptop computers that do not fit into just one single category but rather involve two or more (Guerrettaz et al., 
2021); meaning each assemblage is more than one and less than many, not a multiplicity of bits nor a plurality (Law, 1999, as cited in Fenwick, 2015). For example, an app on a smartphone or tablet is both a virtual environment and a technology installed on a physical entity (i.e., the smartphone or tablet). According to Thorne et al. (2021), using language teaching and learning materials (such as mobile phones) can provide opportunities for second language (L2) learners to cooperate and communicate together and with their environment. The study has illustrated that "communicative action is multimodal, embodied, and embedded in material environments that catalyze action among a heterogeneous array of humans and nonhumans." (p. 120). Thus, human actions such as verbal communication are used systematically to achieve and maintain intersubjectivity, and more importantly, those actions are entangled with nonhuman elements to produce the social.

The following section will briefly discuss CLT, its tenets, and its implementation challenges in EFL/ESL contexts. I do so because the second concern of this paper is to examine CLT challenges in the Saudi educational context from a sociomaterial perspective.

\section{The Implementation of the Communicative Language Teaching Approach}

The best way to define CLT and understand it as an approach might be through understanding its core principles. Brown (2014) identifies four interconnected characteristics of CLT as a direct and straightforward definition. First, within CLT, classroom goals are not restricted to grammatical or linguistic competence. Secondly, organizational language forms are not the central focus but rather aspects that enable learners to use language for meaningful purposes. The third characteristic distinguishing CLT from previous language teaching approaches is that fluency and accuracy are seen as complementary principles underlying communicative techniques. In other words, priority may be given to fluency rather than accuracy to keep learners meaningfully engaged in language use. Finally, in a communicative classroom, authenticity is key, in which students use the language productively and receptively in unrehearsed contexts. Brown (2007) suggests that authenticity of communication often makes it difficult for novice and non-native speaking teachers, who are not very proficient in the target language, to teach effectively as drills, rehearsed exercises, and discussions (in the first language) of grammatical rules seem much more manageable. Brown (2007) notes, however, that such a drawback should not deter communicative goals in the classroom, in which technology can come to the aid of such teachers. This means that language teaching and learning materials are fundamental parts of teaching practices within communicative classrooms, especially in EFL/ESL contexts where teachers and learners might be non-English speakers. Therefore, teaching materials can be seen as equal contributors to the network that assemble and reassemble to generate and constitute communicative practices.

Due to several factors, including a mismatch between some CLT underlying principles and some EFL/ESL educational contexts, empirical evidence has shown that its implementation has proven to be a challenging task (see, for example, Ahmad \& Rao, 2012; Jin \& Cortazzi, 2011 in China and East Asia; Vasilopoulos, 2008 in Korea; Chowdhry, 2003 in Bangladesh). Therefore, a great deal of the research studies that have investigated CLT implementation into EFL contexts reports, almost always, a very similar set of constraints, including class sizes, schedules, lack of resources and equipment (Zhang, 2020; Fang, 2010 in China; Li, 1998 in South 
Korea; Karakas, 2013; Ozsevik, 2010 in Turkey; Alakrash, 2021 in Syria) that hinder its implementation.

In terms of constraints related to limited resources and insufficient language teaching and learning materials (Butler, 2011), several observational studies in the Asian context (Mahmadun Nuby et al., 2020 in Bangladesh; Prapaisit de Segovia \& Hardison, 2008 in Thailand) report those as constraints hindering CLT implementation. In the Saudi context, Al-Mohanna (2010) and Alzaidi (2011) report that Saudi EFL teachers' practices are restricted by the high-density textbooks with insufficient time to teach the textbook from cover to cover, lack of adequate teaching/learning resources, and inadequate examination systems. In summary, the nature of teaching and learning materials and lack of sufficient resources are some of the overarching factors hindering CLT implementation in some EFL/ESL contexts. Therefore, invoking a sociomaterial perspective to understand their role in enhancing or hindering CLT implementation is one of the concerns of this paper. As the findings presented in this paper demonstrate how defining materials from a sociomaterial perspective might be influential in any attempts to successful curriculum implementation.

Even though teaching materials - such as textbooks, facilities, and technological resources - are central elements of communicative language teaching, the issue of how materials can affect CLT implementation has rarely been the focus of research in CLT implementation studies. Thus, the emphasis on CLT challenges from a sociomaterial perspective represents a gap in the literature this paper attends to by examining how materials use shape language teaching and learning environments, in general, and communicative classrooms, in particular. Moreover, this paper engages in the most recent theoretical advancements in the field of language education (Guerrettaz et al., 2021), which have advanced posthumanist (Pennycook, 2018) and materialist (Canagarajah, 2018; Toohey, 2019) orientations highlighting the complexity of meaning-making processes involving materiality within language instructional contexts. Therefore, this paper responds to calls for research on teaching materials to appreciate the complexity of the role that instructional materials play in the broader educational context (Harwood, 2021). Consequently, it addresses what Sørensen (2009) refers to as a "blindness toward the question of how educational practice is affected by materials" (p. 2). In doing so, this paper engages with the argument made by The Douglas Fir Group (2016), advocating the need for new interdisciplinary perspectives and new aims for the 21st-century in the field of applied linguistics so that it "can investigate the learning and teaching of an additional language and the social-local worlds of learners" (p. 20). These new perspectives entail raising questions about language education stimulated from materialist, posthumanist (Toohey, 2019), and sociomaterialist perspectives.

\section{Methods}

This paper draws from an exploratory interpretive study. The purpose of the study was to identify and describe Saudi primary EFL teachers' perspectives of CLT challenges they were facing to understand the well-reported unsatisfactory CLT implementation in the Saudi Arabian context (Bahanshal, 2013). Although the original study collected data from qualitative and quantitative methods, the findings discussed in the current paper were strictly generated from the qualitative strand. Therefore, to maintain the focus of this paper, the methods addressed below are qualitative ones only. 


\section{Participants}

The sample of the study included 15 Saudi female EFL teachers in state primary schools. Six of the participants in the sample participated in both the interviews and classroom observation sessions. A snowball sampling technique was used to gain access to the participants. Once a group of individuals who either had access to or were Saudi EFL teachers at the primary level themselves, those individuals were used as informants who recruited more participants for the study. Due to time and distance constraints and administrative complications, 12 of the participants - for classroom observations in particular - were from urban and rural areas in a major city in Saudi Arabia. As for the remaining three, one was from a different town in the same region, and the other two were teaching in a rural governorate in a different region. A snowball sampling technique was utilized to recruit the participants in the study sample (Cohen, Manion \& Morrison, 2018).

\section{Research Instruments}

Classroom observations

Unstructured classroom observations were used as a supplementary source of data. A nonrating schedule was used to collect handwritten notes during the observation sessions, as it was not my intention to evaluate teachers' behaviors inside the classroom. The purpose was to capture how EFL teachers were or were not able to implement CLT into their practice and to gain insights into the reality of primary EFL classrooms. The observation schedule was designed to comply with the exploratory nature of the project, to capture any unanticipated critical factors and significance of the context, and to catch any context-specific challenges. The observational data gathered deepened my understanding of CLT challenges EFL teachers faced and informed the line of questioning later in the individual interviews. All in all, ten female teachers in nine state primary schools out of the thirteen schools visited were observed, and a total of 17 classroom observation sessions of English lessons at the fourth, fifth, and sixth grades were conducted. A total of around 13 hours of classroom time was observed, in which each observation session lasted between 35 to 45 minutes.

\section{Interviews}

To explore and deeply understand Saudi EFL teachers' perceptions of CLT challenges in their day-to-day teaching practices, individual semi-structured interviews were utilized. The aim was to understand how primary EFL teachers perceived and constructed their social and professional realities. In total, 11 Saudi female teachers, six of whom were from the classroom observations sample, were interviewed. As for the rest, they were recruited through the snowball sampling technique - two were from a rural area in the southern region, one from another city, one was teaching in an afternoon school, and the last one was from the same urban city where the data were collected but from outside the observation sample. Due to distance issues and participants' hesitance to have their voice recorded, the interviews were conducted online through instant messaging (IM) - via WhatsApp messenger. The questions in the interview schedule were adapted based on the initial analysis of trends in the questionnaire data and the notes from the classroom observation sessions.

\section{Data Analysis}

Due to the exploratory nature of this study, Charmaz's (2006) constructivist grounded theory approach was adopted as an analytical framework (Cohen et al., 2018). According to 
Stebbins (2011), exploration and grounded theory would usually be mentioned together because both depend on an inductive line of thinking. Since the semi-structured interviews were the primary data source in this study, six main themes emerged from analyzing the interviewing data. To reflect the complexity of the data, data from the questionnaire and classroom observations were integrated - where applicable - as supporting evidence under each of the research procedures.

\section{Findings}

The findings presented in this paper represent only two themes of the six that emerged in the original study. Namely, the findings addressed here are those related to syllabus, resources, and teaching facilities - i.e., CLT challenges that invoked sociomateriality.

\section{Syllabus Related Challenges}

The majority of teachers in the sample expressed concerns about teaching materials (including the syllabus, textbooks, and supplementary materials provided with the textbook). Teachers in the interview sample expressed concerns about the articulated nature of the syllabus, which restricted their autonomy and limited their ability to teach communicatively. The overwhelming majority of interviewees used words such as 'heavy', 'articulated', 'long', 'demanding', and 'knowledge-packed', to describe the syllabus.

These particular challenges were observed during classroom observations. Given that all observations were conducted over the same period (sometimes observing two teachers in two different schools on the same day), it was noticeable that teachers of the same grade were teaching the same page or part of the lesson in every school. Similarly, it was noticeable in all observation sessions that teachers had to rush through activities and tasks to cover a certain number of pages in the textbook. Thus, in observation session \#9, the teacher was asked about the issue. She explained that by the beginning of each semester, supervisors - from the General Directorate of Education - would send each EFL teacher a very articulated syllabus distribution plan, in which lessons are assigned to specific dates on the calendar so that all teachers would be teaching the same lesson on the same day nationwide. She also explained that if the teacher missed a day either for in-service training or for personal reasons, then she would be obligated to find the time to catch up with the syllabus distribution plan.

These findings indicated that the articulated nature of the syllabus forced teachers to rely more on textbooks, which is inconsistent with CLT principles. Unlike other more traditional language teaching methodologies, CLT - in the context of foreign language teaching - is described as calling for the gradual move from textbooks as principal determiners of the language syllabus towards the use of authentic texts selected by the teachers and learners (Pachler, 2000). This finding is consistent with those of Rahmatuzzman (2018), who has indicated that one of the critical difficulties of implementing CLT is teachers' formal teaching that seems to have more contextual attachment to completing the syllabus than teaching to support communication. This reliance on textbooks and pressure on teachers to strictly do what the textbook instructs them to do might lead to ineffective language teaching and learning. Accordingly, teachers would not have the time to use communicative activities and learners would not have the opportunity to develop their communicative competence. As a result, the communicative goals of the curriculum would not be attained. 
From the lens of sociomateriality, these findings suggest that textbooks can exert power and agency by forcing teachers to adhere to and adjust their practice to align it with the mandated syllabus distribution plan (Fenwick et al., 2011) even when they were clearly struggling with time. According to Fenwick (2015), materials - textbooks in this case - can permit and/or prevent actions, convey knowledge, and become powerful. Thus, in this case, the textbook is playing a performative role, acting together with other elements - in the classroom, including teachers and students - to exclude, invite, change and regulate teaching and learning practices. Thus, materials here wield power by shaping action, conveying knowledge, and collaborating with other social and material elements in the classroom context (Guerrettaz et al., 2021). Yet, sometimes materials can hinder teaching and learning and confound teachers and learners (Miller, 2012). The point here is that the findings indicate that textbook and syllabus distribution plans mandated on Saudi EFL teachers seem more powerful than teachers hindering their ability to implement CLT and deemed their job challenging.

\section{Challenges Related to Limited Resources and Teaching Facilities}

The overwhelming majority of interviewees were particularly critical of the limited resources, students' lack of access to appropriate language learning materials, and proper up-todate educational technology equipment. In all cases, both in the interviewing and observation samples, EFL teachers remarked that it was essential to have an English lab in each school to teach English communicatively. The following excerpt from the interviews illustrates teachers' perspectives on this particular issue:

From my point of view - and I taught English at all levels - quite frankly, all our [ EFL teachers] troubles come down to two core problems limited time and the discouraging environment in our classrooms that does not help appropriate CLT implementation. In my opinion, this can only be solved by assigning an English learning lab equipped with all the resources we need to teach the four language skills appropriately. (Teacher1)

Even teachers in the classroom-observation sample alluded to the notion of an English lab and the magnitude of its effect on their teaching practice. Based on data generated from classroom observations, teachers expressed their frustration about the lack of proper facilities and the discouraging classroom environment. Concerns were also expressed about teachers' and students' lack of access to the internet in schools. Free access to Wi-Fi in states schools is restricted to administrative staff only. Thus, teachers are not given the right to access the school's Wi-Fi, not even for teaching purposes. Talking about this issue, one interviewee said:

"The challenge for me as a teacher is the lack of internet access" (Teacher2)

This issue also arose in discussions about students' backgrounds, especially in underprivileged parts of the city and rural areas. For example, during the pre and post-observation talks with teachers, especially in schools located in disadvantaged communities of the city and schools located in rural areas, they alluded to the notion of students' inability to access the internet.

Teachers' unanimous interest in providing more up-to-date resources for EFL instruction should not be surprising, especially given the ever-increasing roles that digital media play in every aspect of professional and social domains. Overall, research evidence has taken a favorable stance towards the pedagogical use of information and communication technology in Saudi EFL 
classrooms and its potential benefits for learners' engagement, autonomy, and improving their communicative skills (Toro et al., 2019). In accordance with the present findings, previous studies have identified; limited access to suitable equipment and the Internet as obstacles to proper use of digital technologies in EFL instruction (Al-Maini, 2013; Picard, 2019).

These findings invoke sociomateriality and the semiotic relationship between social and material elements in language education contexts. As explained before, material elements in education (including facilities and resources) are usually dismissed or treated as background. However, from a sociomaterialistic point of view, the roles these material assemblages play in creating the reality of the educational phenomenon and how these assemblages become stabilized and durable in ways of producing centers of power are acknowledged (Fenwick \& Doyle, 2018). The findings indicate that from EFL teachers' perspectives, it is not possible to separate effective CLT implementation from technological resources and up-to-date facilities. Teachers' views in this regard show how the existence of facilities and teaching/learning resources (or lack thereof) is participating and creating particular effects on the implementation of the communicative approach into their practice. The findings imply that both elements are entangled and indeterminately connected and that if one is taken out it would not be effective standing alone. Thus, the findings imply that in CLT implementation, there is no distinction between teaching practice (i.e., the social element) and the use of resources and facilities (i.e., the material components).

\section{Discussion}

This section will answer the research questions of the study and interpret the findings. Therefore, the section is organized according to the two questions of the study.

\section{Q1: To what extent do language teaching and learning materials affect CLT implementation in Saudi state schools?}

This study has produced findings that corroborate previous studies that suggested that material elements can exert agency and power in curriculum development and implementation (Fenwick et al., 2011; Landri, 2015). For example, the findings indicated that textbooks, teaching/learning resources, and materials hindered effective CLT implementation. Therefore, it might be helpful to invoke complexity theory and actor-network theory to make sense of these findings. Through this lens, curriculum implementation might be understood as continuous and recursive interactions, produced through relations amongst action and interaction, material elements, social elements, and structural dynamics. Within this view, teaching and learning can be seen as a joint exercise of relational strategies performed by both inanimate (such as textbooks, materials, technology) and animate beings (i.e., teachers and learners) in the classroom. The importance of understanding curriculum development as a complex system might arise because its emergence would only be enabled within educational systems characterized by diversity, decentralization, redundancy, open constraints, and feedback (Johnson, 2001).

Viewing communicative language teaching implementation from a sociomaterial perspective can be beneficial for second language educators. It can help them understand how material elements can influence - limit or enhance teachers' abilities to effectively and meaningfully use communicative activities - language teaching and learning practices. Additionally, this perspective has the potential to shift instructional practices from seeking predictability and control towards understanding teaching and learning as emergent and 
unpredictable systems (Fullan, 2003). Understanding language teaching materials through a sociomaterial lens implies that language teaching materials are not teacher/learner-proof (Harwood, 2021). Thus, the message that needs to filter through here is that material use is an unpredictable practice because teachers and learners may react to and engage with materials differently. Therefore, sociomateriality helps policymakers, curriculum designers, teachers' trainers, and teachers understand that materials cannot be guaranteed to achieve the outcomes they were intended to attain or be as pedagogically effective as their designers anticipated.

\section{Q2: How can sociomateriality extend scholarly efforts to examine curriculum implementation in valuable directions?}

The findings of this study indicated that failure to acknowledge the importance of language teaching and learning materials could only lead to ineffective implementation of curriculum changes. The participants suggested that the lack of an English lab, for example, was an obstacle that stood in the way of teaching communicatively. Thus, the findings have several implications related to the complexity of curriculum implementation processes. In accordance with the present findings, previous studies have demonstrated that the processes of curriculum development and implementation go beyond "stuffing more activities into crowded curricula" (Fenwick, 2015, p. 91). Understanding curriculum development from this perspective would call for viewing reform as an emergence where the end result would be more than the sum of its parts and therefore not predictable from the ground from which it emerged (Fenwick et al., 2011). Fullan (2003) has suggested that the process of educational change should be understood as uncontrollable and unpredictable, as such an understanding would allow using key complexity concepts to design and guide more powerful educational systems. Thus, approaching curriculum development and implementation from this view would call for inclusivity and equity in leadership roles, where all stakeholders, including human and nonhuman elements, would collaborate to implement more profound and sustainable educational reform.

\section{Conclusion}

This paper addressed the challenges of implementing the communicative approach in Saudi state schools from a sociomaterial perspective. The findings indicated that teaching materials such as the textbook exerted power and agency, affecting teachers' ability to teach communicatively. Teachers in the sample showed that lack of proper language teaching facilities and resources was one of the main challenges of implementing the communicative approach in the Saudi state schools. Viewing communicative language teaching from a sociomaterial perspective can be beneficial for second language educators as it can help them understand how material elements can influence - limit or enhance teachers' abilities to effectively and meaningfully use communicative activities - language teaching and learning.

\section{About the author}

Rajaa Mahmoud Fallatah is currently a lecturer in the Department of curriculums and Instructions at the College of Education at Umm Al-Qura University. Her research interests include curriculum development in TESOL, language teacher education, and language education policies. ORCiD: https://orcid.org/0000-0001-5626-8071 


\section{References}

Ahmad, S., \& Rao, C. (2012). Examination washback effect: Syllabus, teaching methodology and the learners' communicative competence. Journal of Education and Practice, 3(15), 173183.

Alakrash, H. (2021). Factors affecting the application of communicative language teaching CLT in Syrian schools. TESOL and Technology Studies, 2(1), 1-14. https://doi.org/10.48185/tts.v2i1.143

Al-Mohanna, A. (2010) English Language Teaching in Saudi Arabian Context: How Communicatively Oriented is it? Journal of King Saud University, 22, 69-88.

Alzaidi, A. (2008). Secondary school head teachers' job satisfaction in Saudi Arabia: The result of a mixed methods approach. Annual Review of Education, Communication and Language Sciences, 5, 161-185.

Bahanshal, D. A. (2013). The Effect of Large Classes on English Teaching and Learning in Saudi Secondary Schools. English Language Teaching, 6(11), 49-59. http://dx.doi.org/10.5539/elt.v6n11p49

Barad, K. (2007). Meeting the universe halfway. In Meeting the universe halfway. Duke University Press. https://doi.org/10.1515/9780822388128

Bax, S. (2003). The end of CLT: A context approach to language teaching. ELT Journal, 57(3), 278-87. https://doi.org/10.1093/elt/57.3.278

Braidotti, R. (2013). Posthuman humanities. European Educational Research Journal, 12(1), 119. https://doi.org/10.2304/eerj.2013.12.1.1

Brown, H. D. (2014). Principles of language learning and teaching ( $6^{\text {th }}$ edition). Pearson Education.

Butler, Y. G. (2004). What Level of English Proficiency Do Elementary School Teachers Need to Attain to Teach EFL? Case Studies from Korea, Taiwan, and Japan. TESOL Quarterly, 38(2), 245-278. doi:10.2307/3588380

Butler, Y. G. (2009). How Do Teachers Observe and Evaluate Elementary School Students' Foreign Language Performance? A Case Study from South Korea. TESOL Quarterly, 43(9), 417-444. doi:10.1002/j.1545-7249.2009.tb00243.x

Canagarajah, S. (2018). Materializing 'competence': Perspectives from international STEM scholars. The Modern Language Journal, 102(2), 268291. https://doi.org/10.1111/modl.12464

Charmaz, K. (2006). Constructing grounded theory: A practical guide through qualitative analysis. SAGE.

Chowdhry, M. R. (2003) International TESOL training and EFL contexts: The cultural disillusionment factor. Australian Journal of Education, 47(3), 283-302. https://doi.org/10.1177\%2F000494410304700307

Cohen, L., Manion, L., \& Morrison, K. (2018). Research methods in education. Routledge Falmer. https://doi.org/10.4324/9781315456539

Didenko, A. V., \& Pichugova, I. L. (2016). Post CLT or post-method: Major criticisms of the communicative approach and the definition of the current pedagogy. In SHS Web of Conferences [proceedings]. EDP sciences: Research paradigms transformation in social sciences, Tomsk, Russia. http://earchive.tpu.ru/handle/11683/33068

Douglas Fir Group. (2016). A transdisciplinary framework for SLA in a multilingual world. The Modern Language Journal, 100(S1), 19-47. https://doi.org/10.1111/modl.12301 
Fenwick, T. (2010), "Rethinking the "thing": Sociomaterial approaches to understanding and researching learning in work", Journal of Workplace Learning, 22(1/2), 104116. https://doi.org/10.1108/13665621011012898

Fenwick, T. (2015). Sociomateriality and learning: A critical approach. The Sage handbook of learning, 83-93.

Fenwick, T., \& Dahlgren, M. A. (2015). Towards socio-material approaches in simulation-based education: lessons from complexity theory. Medical Education, 49(4), 359-367. https://doi.org/10.1111/medu.12638

Fenwick, T., \& Edwards, R. (2010). Actor-network theory in education. Routledge.

Fenwick, T., Edwards, R., \& Sawchuk, P. (2011). Emerging Approaches to Educational Research: Teaching the Sociomaterial. Routledge.

Fenwick, T., \& Landri, P. (2012). Materialities, textures and pedagogies: Socio-material assemblages in education. Pedagogy, Culture \& Society, 20(1), 1-7. https://doi.org/10.1080/14681366.2012.649421

Fullan, M. (2003). Chapter 3: New lessons for complex change. In M. Fullan (Ed.), Change forces with a vengeance (pp. 21-38). London and New York: Routledge Falmer.

Fullan, M. (2016). The New Meaning of Educational Change. New York: Teachers College Press, Columbia University.

Guerrettaz, A. M., Engman, M. M., \& Matsumoto, Y. (2021). Empirically defining language learning and teaching materials in use through sociomaterial perspectives. The Modern Language Journal, 105(S1), 3-20. https://doi.org/10.1111/modl.12691|

Harwood, N. (2021). Coda: An expanding research agenda for the use of instructional materials. The Modern Language Journal, 105(S1), 175-184. https://doi.org/10.1111/modl.12683

Holliday, A. (1994). Appropriate methodology and social context. Cambridge University Press.

Jacobs, G. M., \& Farrell, T. S. (2003). Understanding and implementing the CLT (Communicative Language Teaching) paradigm. RELC Journal, 34(1), 5-30.

Johnson, S. (2001). Emergence: The Connected Lives of Ants, Brains. Cities, and Software. New York: Scribner.

Jin, L., \& Cortazzi, M. (2011). Re-evaluating traditional approaches to second language teaching and learning. Handbook of Research in Second Language Teaching and Learning, 2, 558575.

Karakaş, A. (2013). Is communicative language teaching a panacea in ELT?-Student and teacher perspectives. Journal of Second and Multiple Language Acquisition, 1(1), 1-19.

Kumaravadivelu, B. (2006). Understanding language teaching: From method to postmethod. Routledge.

Latour, B. (2005). Reassembling the social: An introduction to actor-network-theory. Oxford university press.

Li, D. (1998). "It's always more difficult than you plan and imagine": Teachers' perceived difficulties in introducing the communicative approach in South Korea. TESOL Quarterly, 32, 677-703. https://10.2307/3588000

Nuby, H. M. M., Rashid, R. A., Rahman, A. R. M. M., \& Hasan, M. R. (2020). Communicative language teaching in Bangladeshi rural schools. Universal Journal of Educational Research, 8(2), 622-630. https://10.13189/ujer.2020.080235 
Ozsevik, Z. (2010). The use of communicative language teaching (CLT): Turkish EFL teachers' perceived difficulties in implementing CLT in Turkey [Master's thesis]. University of Illinois at Urbana-Champaign.

Pachler, N. (2000). Re-examining communicative language teaching. In K. Field (Ed.), Issues in modern foreign languages teaching, 22-37.

Pennycook, A. (2017). Posthumanist applied linguistics. Routledge. https://doi.org/10.4324/9781315457574

Rahmatuzzman, M. (2018). Communicative language teaching (CLT): Theory vs reality in the context of secondary schools in Bangladesh. Journal of Education and Social Sciences, 10(1), 24-32.

Richards, J. C., \& Rodgers, T. S. (2014). Approaches and methods in language teaching. Cambridge university press.

Sørensen, E. (2009). The Materiality of Learning: Technology and Knowledge in Educational Practice: Learning in Doing: Social, Cognitive and Computational Perspectives. Cambridge: Cambridge University Press.

Sumara, D. J., \& Davis, B. A. (2006). Correspondence, coherence, complexity: Theories of learning and their influences on processes of literary composition. English Teaching: Practice and Critique, 5(2), 34-55.

Stebbins, R. A. (2001). Qualitative research methods: Exploratory research in the social sciences. SAGE Publications Ltd. https://doi.org/10.4135/9781412984249

Thorne, S. L., Hellermann, J., \& Jakonen, T. (2021). Rewilding language education: Emergent assemblages and entangled actions. The Modern Language Journal, 105(S1), 106-125. https://doi.org/10.1111/modl.12687

Tomlinson, B., \& Masuhara, H. (2018). The complete guide to the theory and practice of materials development for language learning. John Wiley \& Sons.

Toohey, K. (2019). The onto-epistemologies of new materialism: Implications for applied linguistics pedagogies and research. Applied Linguistics, 40(6), 937-956. https://doi.org/10.1093/applin/amy046

Vasilopoulos, G. (2008). Adapting communicative language instruction in Korean universities. The Internet TESOL Journal, 14(8), 16-29. https://doi.org/10.1080/15348458.2015.1019783

Woolgar, S., Coopmans, C., \& Neyland, D. (2009). Does STS mean business?. Organization, 16(1), 5-30. https://doi.org/10.1177/1350508408098983

Zhang, L. (2020). An analysis of communicative language teaching approach, an English class and its teaching material. Journal of Advances in Education Research, 5(4), 17 